CBIE-LACLO 2015

Anais do XXI Workshop de Informática na Escola (WIE 2015)

\title{
Programação de computadores para alunos do ensino fundamental: A Escola de Hackers
}

\author{
Adriano Canabarro Teixeira ${ }^{1}$, Neuza Terezinha Oro ${ }^{1}$, Fernanda Batistela ${ }^{2}$, João \\ Alberto Ramos Martins², Ariane Mileidi Pazinato ${ }^{3}$, \\ ${ }^{1}$ Instituto de Ciências Exatas e Geociências - Universidade de Passo Fundo (UPF) \\ 99.052-900 - Passo Fundo - RS - Brazil \\ ${ }^{2}$ Faculdade de Educação- Universidade de Passo Fundo (UPF) \\ ${ }^{3}$ Faculdade Meridional (IMED) - Passo Fundo, RS - Brazil \\ \{teixeira,neuza\}@upf.br, batistela.fernanda@gmail.com, \\ joaom@pmpf.rs.gov.br, ariane.pazinato@imed.edu.br
}

\begin{abstract}
Computer programming have been used lately as a tool in informatics labs and educational practices at schools and institutions in Passo Fundo/RS through the project Escola de Hackers, which had its first edition in 2014, offering workshops from may to december in informatics labs of 21 municipal schools. The groups were formed by students from the 6th to 9th year of elementary school, using the programming environment Scratch. This paper aims presenting the Escola de Hackers project, its organization, methodology and results acquired in its first edition.
\end{abstract}

Resumo: A programação de computadores vêm sendo utilizada como ferramenta nos laboratórios de informática e nas práticas educacionais em instituições escolares de Passo Fundo/RS através do projeto Escola de Hackers, que teve sua primeira edição em 2014, oferecendo oficinas durante o período de maio a dezembro nos laboratórios de informática de vinte e uma Escolas Municipais. As turmas foram formadas por alunos do $6^{\circ}$ ao $9^{\circ}$ anos do Ensino Fundamental, utilizando o ambiente de programação Scratch. Este artigo tem por objetivo apresentar o projeto Escola de Hackers, sua organização, metodologia e os resultados obtidos na primeira edição.

\section{Introdução}

A informática educativa já faz parte do cotidiano educacional a mais de duas décadas. Sua gênese foi, sem sombra de dúvidas, o desenvolvimento de um software onde era possível, a partir de comandos dados através do teclado, movimentar uma pequena tartaruga na tela dos computadores da época. Trata-se da linguagem interpretada LOGO desenvolvida na década de 60 pelo matemático Seymour Papert que acreditava que os computadores, até então destinados ao mundo dos negócios e à ciência avançada poderia ser um instrumento de aprendizagem poderoso na mão das crianças.

No Brasil, a informática educativa teve seu início ainda na década de 70 e a primeira ação ed vulto foi tomada em 1981, quando um grupo criado por representantes do MEC, da Secretaria Especial de Informática, do CNPq e da Finep, construíram e divulgaram o documento "Subsídios para a Implantação do Programa Nacional de 
CBIE-LACLO 2015

Anais do XXI Workshop de Informática na Escola (WIE 2015)

Informática na Educação”, que apresentou o primeiro modelo de funcionamento de um futuro sistema de informática na educação brasileira ${ }^{1}$. Estranhamente, 34 anos depois desta iniciativa e, mesmo reconhecendo que a tecnologia não é panacéia, podemos identificar que embora tenhamos avançado - e muito temos de avançar ainda - na disponibilização de computadores, e que estes equipamentos digitais são poderosos democratizadores de acesso à informação, a bens culturais e a espaços de comunicação, não se verifica qualquer tipo de avanço significativo na educação que possa ser atribuído à presença destes aparatos.

De forma genérica, podemos afirmar que a informática educativa no Brasil passou por três fases e que temos realidades em que a primeira fase ainda é uma necessidade. A primeira, quando ainda se ouvia ecoar as ideias de Papert de forma consistente em alguns espaços - acadêmcos estritamente, buscava o lógico processo de informatização. A segunda fase pressupunha um espaço informatizado que precisava de dois outros complementos: Softwares educativos e conexão, nesta ordem. Foram tempos de muita produção acadêmica e investimento financeiro para, primeiro oferecer softwares para os hardwares distribuídos e, segundo, conectar os computadores à rede mundial de computadores, momento em que cresceu o interesse, e a demanda, por ambientes virtuais de aprendizagem. A terceira fase explorava as metodologias interdisciplinares de apropriação das tecnologias digitais como espaços de diálogo entre diferentes disciplinas em torno de um projeto de aprendizagem. Embora considere a terceira fase a mais importante e significativa das três, é preciso reconhecer que, do ponto de vista de incremento educacional ao processo de aprendizagem dos estudantes foi mínimo, se é que podemos atribuir às tecnologias, o que não acreditamos.

Desta forma, a dois anos, o Grupo de Estudo e Pesquisa em Inclusão Digital da Universidade de Passo Fundo tem focado seus esforços de pesquisa e de extensão na exploração daquilo que na década de 60 foi o início da informática educativa que conhecemos: a programação de computadores. O grupo acredita que o ato de programar pode desenvolver competências cognitivas que terão desdobramento positivos sobre a aprendizagem dos estudantes em outras áreas do conhecimento. Desta premissa nasceu o projeto Escola de Hackers, uma iniciativa da Prefeitura Municipal de Passo Fundo com apoio de três instituições de ensino superior do município que tem por objetivo, além de criai uma alternativa de utilização qualificada dos laboratórios de informática, oportunizar espaço para o desenvolvimento de competências na área de programação de computadores e de raciocínio lógico matemático para os estudantes. Posto isto, este artigo tem por objetivo apresentar as premissas do projeto Escola de Hackers, suas etapas, metodologia e resultados no ano de 2014.

\section{Contextualizando a programação de computadores}

Segundo Rushkoff (2012), “Os primeiros computadores foram construídos por hackers”. Hacker é conhecido como um sujeito criativo e que se dedica, com intensidade a modificar

$1 \mathrm{O}$ detalhamento deste histórico pode ser encontrado em http:/portal.mec.gov.br/seb/arquivos/pdf/profunc/infor aplic educ.pdf. 
CBIE-LACLO 2015

Anais do XXI Workshop de Informática na Escola (WIE 2015)

dispositivos, programas e redes de computadores, respeitando as leis. Por isso o nome de Projeto Escola de Hackers, o qualtem como objetivo geral oportunizar espaço para o desenvolvimento de competências na área de programação de computadores e de raciocínio lógico matemático para os estudantes. Por volta da década de 1970, os computadores eram supostamente difíceis de usar, pois não havia diferença entre programá-los e operá-los. Portanto, estas máquinas eram pensadas e usadas para criar qualquer coisa, como se fossem tábuas rasas, as quais possibilitavam a liberdade de escrever softwares. A partir deste contexto, segundo Rushkoff (2012, p.142), “programar é imensamente poderoso” e não é difícil de aprender.

Na visão de Papert (1985), comunicar-se com o computador é um processo natural do ser humano. É ele quem deve programar o computador e não ao contrário, o computador ensinar as crianças. Nesta perspectiva, o ser humano assume um sentimento de domínio, ou seja, de controle sobre a máquina. Assim sendo, o autor afirma que programar significa comunicar-se com o computador numa linguagem que tanto ele quanto o homem possam entender. Uma das linguagens de programação desenvolvidas por Papert é a LOGO, conhecida como linguagem da tartaruga. É interativa, de fácil compreensão e pode ser direcionada à indivíduos de todas as idades. Foi criada em 1968 com o objetivo de fazer os indivíduos criarem, pensarem, inventarem e experimentarem, assim, é considerado um ambiente de aprendizagem, pois o indivíduo vai usar comandos para movimentar o animal cibernético para diferentes caminhos, sob seu próprio domínio.

Programar envolve uma série de capacidades, por isso e por outros fatores, a programação está diretamente ligada à aprendizagem. Segundo Papert (1994, p.37), “a melhor aprendizagem ocorre quando o aprendiz assume o comando". No caso da programação, é o indivíduo que tem o comando sobre o ambiente e sobre o computador. Papert (1994, p. 51) em seu livro A máquina das crianças, afirma que "uma das principais diferenças entre aprender na escola e todas as outras aprendizagens” é que por meio do LOGO, por exemplo, o indivíduo aprende e estará em constante aprendizado, pois estará sempre criando algo sobre aquilo que já aprendeu. Também, segundo o autor, este ambiente não é algo para ser usado e depois deixado de lado, isto porque, o indivíduo sente que está no poder. Afirma ainda, que é uma sensação boa de controle, ao fazer com que uma das mais poderosas tecnologias, o computador, obedeça algum comando seu. Assim, o ser humano deixa de ser um mero receptor e passa a ser um idealizador de ideias.

Segundo Papert (1985), uma característica relevante da programação de computadores é que a criança dificilmente vai acertar na primeira vez que programar, então, ela vai persistindo e resolvendo os problemas até chegar ao resultado que pretende, diferentemente do modelo de educação onde existe o acertou e o errou, o que retarda a aprendizagem de muitas crianças. Assim, todos aprendem por meio de seus próprios erros ou pelos erros dos seus colegas, portanto, quem programa acaba se tornando mais tolerante com relação aos seus erros. Além disso, se a criança não estiver convivendo num ambiente onde só existe o certo ou errado, ela vai se tornar mais criativa, pois terá que achar meios para resolver seu erro. Percebe-se que, programas, recursos educacionais, softwares, objetos educacionais, os quais vêm instalados em computadores de muitas instituições 
CBIE-LACLO 2015

Anais do XXI Workshop de Informática na Escola (WIE 2015)

escolares, e disponíveis no sistema operacional Linux educacional, não estão trazendo uma significância em termos de aprendizagem aos alunos. O ambiente escolar, bem como a sala de aula, está apresentando, nas palavras de Papert (1985) ambientes de aprendizado ineficientes aos alunos.

Inspirado no software de autoria LOGO, surge o Scratch, o qual foi partilhado com o mundo, pela primeira vez, em 15 de Maio de 2007 e desenvolvido em virtude do crescente distanciamento entre a evolução tecnológica e a fluência tecnológica dos cidadão. MitchelResnick e outros pesquisadores, no vídeo "Scratch, Media LabVideo" explicam sobre as potencialidades atribuídas ao indivíduo que programa através deste ambiente e Jay Silver afirma gostar "da idéia de uma ferramenta que possa ser utilizadasem escolas, mas que induzem o aprendiz a usarem sozinhos" (1:38), ou seja, ele apoia a ideia de usar o Scratch nas escolas, desde que alunos tenham a liberdade de criarem de forma autônoma.

O Scratch, cujo slogané imagina, programa, partilha, possibilita a criação de programas que controlem textos, como por exemplo, em forma de histórias interativas, animações, jogos, música e arte, os quais podem ser compartilhados na web, favorecendo a aprendizagem de importantes ideias Matemáticas e computacionais. Segundo Figueiredo, Marques (2010), por meio do Scratch, o indivíduo aprende a pensar criativamente e a trabalhar de forma colaborativa, ou seja, na interação social com o outro ou com projetos de outras pessoas.

Marques (2009, p. 32) menciona que "Apesar do ambiente estimulante, que motiva e propicia o trabalho autónomo, permite uma iniciação fácil e não implica o ensino formal de conceitos de programação". Assim, a programação de computadores é uma alternativa ao aprendizado dos indivíduos e o Scratch, uma opção interativa de trabalhar a programação nas instituições de ensino. Os desdobramentos que se percebe em indivíduos que programam são positivos, partindo do princípio que eles têm o domínio sobre o ambiente e, portanto sobre o computador. Assim, tornam-se mais autônomos e conseguem ter controle sobre suas ações, refletindo na melhora de sua aprendizagem.

\section{O Projeto Escola de Hackers}

O Projeto Escola de Hackers ${ }^{3}$ consiste em um conjunto de ações que oportunizam o aprendizado de técnicas e habilidades de programação de computadores para alunos do $6^{\circ}$ ao $9^{\circ}$ anos do Ensino Fundamental, entre as idades de 11 e 14 anos, utilizando o softwareScratch. Têm como objetivo geral oportunizar espaço para o desenvolvimento de competências na área de programação de computadores e de raciocínio lógico matemático para os estudantes e professores das Escolas Municipais de Ensino Fundamental (EMEF) de Passo Fundo.

A ideia nasceu das Olimpíadas de Programação de Computadores para alunos do Ensino Fundamental ${ }^{4}$, organizada pela Universidade de Passo Fundo em parceria com a

2 Site oficial do Scratch: <http://scratch.mit.edu/>. Acesso em 11 jan. 2015.

3 Video explicativo sobre o Escola de Hackers: http://goo.gl/DFnSTH. Acesso em 11 jan. 2015.

4 Mais informações em http://olimpiada.mutirao.upf.br/programacao/. 
CBIE-LACLO 2015

Anais do XXI Workshop de Informática na Escola (WIE 2015)

Prefeitura Municipal. O apoio foi do GEPID da UPF, dos projetos de Extensão Mutirão pela Inclusão Digital e Interação das Olimpíadas Brasileiras de Matemática para as Escolas Públicas com o Ensino da Matemática da UPF e do Núcleo de Tecnologia Educacional (NTE) da $7^{\text {a }}$ Coordenadoria Regional de Educação (CRE). O Projeto Escola de Hackers é uma realização da Prefeitura Municipal de Passo Fundo (PMPF), organizado pela Secretaria de Educação (SME), com o apoio da Universidade de Passo Fundo (UPF), da Faculdade Meridional (IMED) e do Instituto Federal Sul-Rio-grandense (IFSul). Têm pretensão de ser estendido às demais Escolas do Município no decorrer dos próximos anos.

Teve seu início em 2014, com a participação de vinte e uma escolas, distribuídas em equipes de no mínimo quinze e no máximo vinte alunos do Ensino Fundamental. As equipes são atendidas por monitores, alunos(as) das Instituições de Ensino Superior (IEs) envolvidas, os(as) quais desenvolveram oficinas semanais, no turno inverso do horário escolar dos alunos, no laboratório de informática das escolas, entre o período de maio à dezembro. As oficinas tiveram o acompanhamento da equipe organizadora do Projeto, a qual se reuniu semanalmente com os monitores, no período de fevereiro a dezembro, no Grupo de Estudo e Pesquisa em Inclusão Digital (GEPID), da UPF.

Os objetivos específicos do Projeto foram especificamente: propiciar atividades que aprimorarem o raciocínio lógico matemático; conhecer ambientes, linguagens e técnicas de programação de computadores; organizar material de apoio didático pedagógico; criar alternativas de utilização para os laboratórios de informática das escolas públicas; proporcionar atividades que visam o desenvolvimento de processos criativos, sistemáticos e colaborativos de aprendizagem; fomentar o interesse em torno das áreas de informática e Matemática.

\subsection{Etapas do Projeto Escola de Hackers}

De uma forma genérica, o projeto se desenvolve a partir das seguintes etapas: Preliminar [Etapa 1], Execução [Etapa 2] e Formatura [Etapa 3]e Avaliação do projeto [Etapa 4].

[Etapa 1] Preliminar: Consiste nas definições dos conteúdos a serem desenvolvidos, elaboração de material didático contendo informações da ferramenta a ser utilizada, tarefas de fixação e construção de desafios. Estas atividades serão organizadas em módulos. Os módulos consistem em um conjunto de ações que contemplam os conteúdos estabelecidos. Nesta etapa tem o contato com as Escolas Municipais para apresentação do projeto Escola de Hackers e convite de participação. Divulgação do projeto, Inscrição das Escolas Municipais, Organização e distribuição dos monitores, cronograma de ações junto às escolas. Formação de monitores (acadêmicos bolsistas das IES envolvidas) e Professores Hackers das Escolas Municipais de Passo Fundo participantes do Projeto, utilizando o material didático elaborado com as orientações didáticas e metodológicas e solenidade de abertura da Escola Hacker.

[Etapa 2] Execução: A etapa de execução se referiu à implementação das ações da Escola de Hackers. Dentre as ações desenvolvidas, destacam-se a realização de oficinas semanais com duração de 2 horas, conduzidas pelos monitores, nos laboratórios de informática das 
CBIE-LACLO 2015

Anais do XXI Workshop de Informática na Escola (WIE 2015)

escolas inscritas. Nessa etapa, utilizou-se o material elaborado na etapa preliminar que, no decorrer do ano foi sofrendo alterações em função dos desdobramentos das oficinas, dos relatos dos monitores e da observação da equipe organizadora. Para a realização das atividades nas escolas, optou-se pelo Scratch para desenvolver as atividades do Escola de Hackers porque o mesmo já vinha sendo utilizado na Olimpíada de Programação de Computadores, juntamente com outros projetos do GEPID a aproximadamente dois anos e, conforme estudos de pesquisadores do grupo, o software reflete positivamente no processo de ensino e aprendizagem de alunos. O ambiente Scratch é uma linguagem de programação com finalidade educativa, desenvolvida no Instituto de Tecnologia de Massachussets (MIT), o qual possui duas versões gratuitas, o Scratch, direcionado para crianças a partir dos oito anos de idade e o Scratch $J r$, projetada para crianças entre cinco e sete anos.

As oficinas do Projeto, foram ministradas por seis monitores, acadêmicos bolsistas das Instituições de Ensino Superior (IES) envolvidas e alunos do Programa Institucional de Bolsa de Iniciação à Docência - PIBID da Licenciatura em Matemática da UPF, e aconteceram, semanalmente, entre os meses de maio a dezembro, no turno inverso às atividades escolares, nos turnos da manhã e da tarde, de terça a sexta-feira, delimitadas à três horas cada e realizadas no laboratório de informática das escolas inscritas.

As atividades envolveram orientação, elaboração, sistematização e execução de projetos, utilizando a programação de computadores na resolução de desafios, jogos e animações, com o objetivo de desenvolver a criatividade, o raciocínio lógico-matemático e as competências de trabalho em grupo. Todas as atividades pressuporam o reconhecimento da tecnologia como elemento de consolidação do raciocínio lógico-matemático em torno de situações-problema. As oficinas foram organizadas de forma que todos(as) os(as) monitores(as) pudessem trabalhar o mesmo conteúdo, com as mesmas estratégias em todas as escolas. Estas atividades também foram acompanhadas por alunos concluintes de cursos de Graduação, de iniciação científica, de mestrado e doutorado das IES parcerias que realizam suas pesquisas no âmbito do Projeto ou de sua temática.

Nas primeiras aulas com os alunos, foi apresentado a interface do software Scratch, o site do software e atividades simples, que envolveram a troca de palco e de sprites, cores, sons, trajes ou fantasias, avançando posteriormente para atividades que envolveram todos os comandos ou roteiros, apresentando noções de variáveis, condicionais e listas para, enfim, dar condições e liberdade para que os estudantes construíssem seus projetos de jogos, animações e histórias. Tudo isso foi registrando num documento identificado como caderno didático ${ }^{5}$, o qual apresenta propostas pedagógicas prontas para serem aplicadas ou adequadas às futuras oficinas de programação do Projeto. As equipes foram formadas por quinze à vinte alunos, os quais foram selecionados pela equipe diretiva das escolas e matriculados no ambiente de controle do site do mutirão ${ }^{6}$. Foi delimitado pela equipe diretiva do Projeto que poderiam participar somente estudantes do $6^{\circ}$ ao $9^{\circ}$ anos do Ensino Fundamental que tivessem uma autorização de participação assinadas pelos pais ou responsáveis e uma ficha cadastral para melhor conhecer cada aluno, descobrir se possuíam

5 Acessível em http://mutirao.upf.br/escoladehackers/?page id=58 .

6 Acessível em http://mutirao.upf.br/controle . 
CBIE-LACLO 2015

Anais do XXI Workshop de Informática na Escola (WIE 2015)

alguma deficiência e questionar sobre seus objetivos em participar deste Projeto.

[Etapa 3] Formatura: Nesta etapa foi realizado a formatura com entrega de certificados fornecidos pela Secretaria Municipal de Educação durante a realização da terceira edição da Olimpíada de Programação de Computadores para Estudantes do Ensino Fundamental, realizada em 2014.

\subsection{Metodologia de trabalho}

A partir de reuniões realizadas em 2013, entre componentes da comissão organizadora do Projeto, construiu-se um documento identificado como caderno didático, o qual apresenta definições de conteúdos e metodologia para serem desenvolvidos no decorrer das oficinas. Assim, deu-se inicio às atividades do Projeto Escola de Hackers e identificou-se esta etapa como preliminar. Quando finalizado este cronograma do caderno didático, então, por meio de reuniões gerais com a presença das(os) seis monitoras(es), entre fevereiro e dezembro de 2014, foram repassadas as atividades semanais a eles, tendo em vista que primeiramente aplicavam-se numa das vinte e uma escolas participantes, identificada como Escola Piloto. Ficou definido que, antes de iniciar as oficinas, as(os) monitoras(es) apresentavam resumidamente o conteúdo a ser desenvolvido e no final, o conteúdo da aula posterior. Para isso, sugeriu-se o uso do projetor multimídia da escola, assim as(os) alunas(os) visualizariam o ambiente de programação facilitando as explicações. Uma vez que a conexão nas escolas nem sempre permitia a utilização do site do Scratch para a criação de contas para cada participante do projeto, a cada finalização de projetos por parte dos alunos, o(a) monitor(a) podia enviá-los para o e-mail escola.hackers.pf@gmail.com.

Os conteúdos foram divididos em três blocos. O bloco 1 foi identificado como Conhecendo o ambiente e explanou-se sobre os nomes dos campos, abas, botões da tela inicial do Scratch e apresentou-se os blocos lógicos para melhor explicar as condicionais se, então e senão. Uma das atividades desenvolvidas fora do laboratório de informática e que esteve diretamente relacionada aos blocos lógicos pode ser conhecida em https://goo.gl/jPQd5L. Depois desta primeira explanação, possibilitou-se a criação de desafios simples como, por exemplo, inserir e criar palcos, sprites, importar os desafios para o site do ambiente de programação e do site para o computador. No bloco 2, planejouse descrever os comandos necessários para programação, roteiros de movimento, controle, eventos, aparência, manipulação de som, operadores, caneta, variáveis. Posteriormente, lançou-se uma porção de atividades, para as quais os enunciados ${ }^{7}$ foram impressos e entregues aos estudantes no inicio de cada oficina para que pudessem avançar progressivamente nas suas resoluções. Sempre que os alunos demonstravam ter dúvidas, como regra do Projeto, eles levantavam a mão e as(os)monitoras(es) iam até eles para esclarecimentos. Se a percepção de dúvidas era generalizada, então, a mesma fora esclarecida a turma toda.

O bloco três, por sua vez, ocupou-se da criação de jogos. onde se sugeriu algumas sugestões de jogos e passos para criação ${ }^{8}$. Nesta oportunidade, os alunos optaram pelo jogo

7 Acessível em https://goo.gl/RXOlgL. 8 Acessível em https://goo.g//OEF7GJ . 
CBIE-LACLO 2015

Anais do XXI Workshop de Informática na Escola (WIE 2015)

a ser programado conforme sua preferência, o que acabou demandando vários encontros para finaliza-lo. Também, alguns alunos salvavam a programação do jogo realizada no decorrer das oficinas e, em casa, dedicavam-se a melhorá-lo. No final, reuniu-se todos os alunos de cada uma das escolas participantes para assistirem às apresentações dos jogos. Este momento foi pensado previamente junto à direção escolar a fim de definir um turno no final do ano para este fim. O ambiente foi preparado com cadeiras dispostas para os convidados assistirem às apresentações ${ }^{9}$ que foram explicadas detalhadamente por cada dupla a partir do projeto multimídia e microfone. Este momento constituiu-se no encerramento das atividades do Projeto nas escolas, sendo que o encerramento oficial do Projeto e a entrega de certificados ocorreu no final de $3^{\text {a }}$ Olimpíada de Programação de Computadores na Universidade de Passo Fundo. É importante salientar que durante todo o processo foram realizadas observações e entrevistas pontuais com todos os participantes do processo, incluindo a equipe diretiva e professores de outras disciplinas.

\section{Desdobramentos e resultados}

Por meio da participação nas reuniões e do acompanhamento nas escolas, percebeu-se pouco ou nenhum envolvimento do(a) diretor(a) e coordenador(a) nas oficinas do Projeto. Segundo fala dos(as) monitores(as), alguns(as) diretores(as) passavam esporadicamente no laboratório de informática para cumprimentar o(a) monitor(a), perguntar se precisavam de alguma coisa, verificar se os alunos estavam presenciando às aulas e participando das atividades. Dentre os(as) vinte e um(a) coordenadores(as), somente uma se mostrou interessada pelo Scratch e acompanhou as oficinas de sua escola do inicio ao final do Projeto. Outro aspecto interessante apontado pelos monitores(as), nas reuniões e percebido nas entrevistas com diretores(as), refere-se ao fato de que o Projeto foi divulgado somente para os alunos selecionados e não para outras turmas e alunos das escolas, fato que, avaliou-se como um dos motivos da desistência de alguns alunos. Ainda, segundo os(as) monitores(as), a informações sobre o Projeto não fluíam dentro das escolas, pois, conforme depoimentos, poucos contavam à seus colegas e/ou professores o que desenvolviam no decorrer das oficinas.

Com relação às entrevistas, ao questionar sobre as percepções dos(as) diretores(as) referente à Escola de Hackers,a maioria empolgou-se com esta oportunidade lançada aos alunos e disseram que $o$ projeto possuía um potencial de êxito considerável. No total, quatorze disseram não estar acompanhando a Escola de Hackers e não compreenderam seu objetivo e seis responderam que sabem do que se trata e entenderam que os alunos participam das oficinas para programarem computadores através do Scratch. Além disso, consideram o Projeto como algo muito bom, pois trabalha o raciocínio lógico dos alunos e as habilidades. Também, estas(es) diretoras(es) gostariam de acompanhar mais as aulas do Projeto, porém, não conseguem em função de suas atividades na direção escolar. Em entrevista com a professora de Português e diretora de uma das escolas, elas trazem pontos positivos do Projeto.

Eu achei fantástico o projeto, acho que é por ai mesmo, ou seja, explorar a criatividade deles, a concentração, que eles desenvolvam as coisas, que eles vejam que é possível, não é

9 Neste link https://goo.gl/YRec06 é possível visualizar alguns registros fotográficos. 
CBIE-LACLO 2015

Anais do XXI Workshop de Informática na Escola (WIE 2015)

que seja difícil, ou seja, que há esta possibilidade. Até pra alguma coisa em termos de futuro, pra faculdade, pra curso. E essa coisa de tecnologia é o chão deles, eles amam. [Professora de Português].

Eles vem porque eles realmente querem. Quando uns começaram a desistir dos Projetos lançados pela escola, foi questionado do porque, mas os que estão vindo é porque eles gostam! Por exemplo, o aluno E, ele desistiu do inglês para vir na Escola de Hackers. [Diretora].

Em maioria, os alunos reconheceram desdobramentos em seu desempenho cognitivo a partir da participação no Projeto. Uma das alunas entrevistadas diz que sentiu diferença em seu raciocínio lógico.

Desenvolveu bem mais o raciocínio, de você ler e entender, você ta fazendo as coisas ali você tem que pensar antes pra chegar em algum lugar, e isso ajudou bastante, eu vejo em todas as matérias que ajudou o raciocínio de poder juntar uma coisa com a outra mais rápido do que eu juntava antes. [Aluna].

Vale constar que um dos objetivos do Projeto era criar alternativas de utilização para os laboratórios de informática das escolas públicas. Nove diretoras(es) disseram que não perceberam reflexos e que o uso do laboratório continuou o mesmo. Destas, onze afirmaram ver reflexos positivos no uso do laboratório e perceberam isto nas falas de alguns alunos. Uma das falas foi que: as crianças tem essa vontade de vir ao laboratório e mais agora com essa questão desse Projeto, despertou mais ainda! A maioria dos(as) diretores(as) dizem que os alunos gostariam de usar o laboratório no turno inverso às atividades escolares e gostariam de ir em mais períodos, além dos que estão reservados à eles. Além disso, pediam mais seguidamente, aos professores, para irem ao laboratório. Os professores responsáveis pelos laboratórios dizem que os alunos estão mais centralizados no objetivo das aulas no laboratório. Também, embora a participação dos responsáveis pelos laboratórios tenha sido baixa, é preciso relatar que se percebeu que alguns professores que antes não usavam, agora estão levando seus alunos no laboratório. Ainda, alunos que não estudavam na escola também se interessaram pelo Projeto e pediram para participar.

De modo geral, todas as etapas pensadas para o Projeto foram desenvolvidas dentro do prazo determinado, ou seja, até dezembro de 2014 e, das trinta e seis EMEFs do Município, convidadas a participarem, vinte e uma se inscreveram e persistiram até o final. Inicialmente, todas as equipes preenchiam na média de 15 a 20 alunos e alguns desistiram no decorrer dos meses pelos seguintes motivos: começou a trabalhar; precisou ajudar sua família; começou um outro curso, o qual coincidia com o horário do Projeto; optou por participar de outro projeto oferecido pela escola; não se interessou pelo Scratch. Assim, totalizou-se vinte e duas equipes de alunos e formação de 312 alunos do $6^{\circ}$ ao $9^{\circ}$ anos da educação básica, sendo 173 alunas do sexo feminino e 139 alunos do sexo masculino. Portanto, o Projeto atingiu um número menor de participantes pretendidos, os quais se estruturavam entre 540 a 720 estudantes das EMEFs se todas as escolas tivessem participado. Para finalizar o Projeto, em dezembro de 2014, sete equipes de sete escolas participantes do Projeto, se inscreveram na Olimpíada de Programação de Computadores e nenhuma delas se classificou dentre as três primeiras colocadas. De qualquer forma, é importante salientar que na $2^{a}$ Olimpíada de Programação, tivemos somente uma escola 
CBIE-LACLO 2015

Anais do XXI Workshop de Informática na Escola (WIE 2015)

inscrita.

\section{Conclusão}

Embora este artigo tenha por objetivo tão somente apresentar o projeto Escola de Hackers e seus desdobramentos, é importante registrar algumas reflexões que julgamos pertinentes acerca do processo de resignificação e qualificação da informática educativa no contexto brasileiro e, talvez, internacional. $\mathrm{O}$ primeiro diz respeito à necessidade de envolvimento orgânico de dirigentes e professores em atividades que busquem a apropriação criativa e inovadora dos recursos digitais presentes na escola. Embora esta demanda não seja nova, nem tampouco somente da área de informática educativa, ficou evidente no decorrer do projeto. Especificamente dentro do contexto da Escola de Hackers, que propõe uma atividade em que a tecnologia é fim e não meio, surge a demanda por processos formativos de docentes muito mais consistente que, dentre outros aspectos, exige um envolvimento integral dos professores responsáveis pela tecnologia em sala de aula.

O relato de alguns diretores, diferentemente daquela feita por professores de disciplinas específicas, aponta que não foi possível notar diferenças significativas nos estudantes participantes do projeto. Tal percepção provavelmente decorra do distanciamento do projeto por parte da gestão da escola, compreensível em certa medida e que foi corroborado pelo número de diretores que relataram não estar acompanhando o projeto e, portanto, não compreendiam seu objetivo. Tal contexto, exige um maior acompanhamento em suas novas edições por parte da equipe organizadora a fim de verificar se, e de que forma, a participação no projeto tem reflexos no desenvolvimento acadêmico dos participantes.

\section{Referencias bibliográficas}

GEPID, Universidade de Passo Fundo. Olimpíada de programação de computadores para o ensino fundamental. Disponível em: <http://olimpiada.mutirao.upf.br/programacao/? page_id=15>. Acesso em: 10 jan. 2015.

jan. 2015.

MARQUES, Maria T. P. M. (2012). Recuperar o engenho a partir da necessidade, com recurso às tecnologias educativas: contributo do ambiente gráfico de programação Scratch em contexto formal de aprendizagem. Universidade de Lisboa, 2009. Disponível em: $\quad<$ http://eduscratch.dgidc.min-edu.pt/index.php? option=com_docman\&task $=$ doc

PAPERT, Seymour. A máquina das crianças: repensando a escola na era da informática. Porto Alegre: Artes Médicas, 1994.

PAPERT, Seymour. Logo: computadores e educação. São Paulo: Brasiliense, 1985.

RUSHKOFF, Douglas. As 10 questões essenciais da era digital. Programe seu futuro para não ser programado por ele. São Paulo: Saraiva, 2012.

SCRATCH. ABOUT Scratch (Scratch Documentation Site). Disponível em http://info.scratch.mit.edu/About_Scratch. Acesso em: 11 dez de 2014. 